\title{
"The Killer Placenta" - a threat to the lives of young women giving birth by cesarean section
}

\author{
Wojciech Cnota $\oplus^{\oplus}$, Ewa Banas® ${ }^{\circledR}$, Daria Dziechcinska-Poletek, Ewa Janowska®,

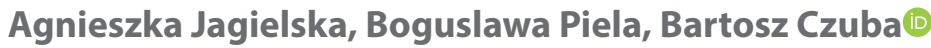 \\ Clinical Department of Perinatology, Gynaecology and Obstetrics in Ruda Slaska, Medical \\ University of Silesia, Ruda Slaska, Poland
}

\begin{abstract}
Objectives: It is necessary to create a universal algorithm for the management of placenta accreta spectrum in order to minimize morbidity and mortality in young patients giving birth by caesarean section.

Material and methods: This was a retrospective study of seven women before the age of 30 selected out of larger group of 40 pregnant patients. The patients were hospitalized in the Clinical Department of Perinatology, Gynecology and Obstetrics in Ruda Slaska, which is a $3^{\text {rd }}$ level reference department. The inclusion criterion was the suspicion of placent accreta spectrum, based on clinical condition, ultrasound examination and magnetic resonance imaging.

Results: A patient with a diagnosed placenta accreta spectrum should be provided with a highly specialized 3rd level referential center by an experienced multidisciplinary team of specialists. There should be free access to the blood bank, adult intensive care unit and neonatal intensive care unit. According to the results of this study, the recommended time of cesarean section is $34+0-36+6$ weeks of pregnancy. Hysterectomy after the cesarean section is a method of choice for a placenta increta or percreta. It is the most difficult surgery in obstetrics, with a high risk of intraoperative complications. Damage to the urinary system is the most common complication of perinatal hysterectomy. Preoperative placement of ureteral catheters reduces the risk of intraoperative damage.
\end{abstract}

Conclusions: It is necessary to plan individual procedure for women who has low-lying or previa placenta, and who has history of prior cesarean section - in this group the risk of placenta accreta spectrum is higher.

Key words: cesarean section; placenta accreta spectrum; placenta invasion; placenta increta; algorithm

Ginekologia Polska 2022; 93, 4: 314-320

\section{INTRODUCTION}

"The Killer Placenta" defines a placenta accreta spectrum (PAS), which is a consequence of abnormally coherent placenta and invasion to the uterine wall. Placenta accreta spectrum was divided into three categories: placenta creta is characterized by abnormal penetration of the placental villi, which cross the endometrial border, penetrating the superficial muscular layer of the uterine wall. It is possible to spontaneously separate the placenta creta after having a baby, it can often be complicated by increased placental bleeding. We can recognize the placenta increta when the placenta villi invade the myometrium, and placenta percreta when villi penetrate the myometrium and penetrate through the uterine serosa. Placental villi can also grow into the bladder or intestine wall [1]. The most popular hypothesis about the etiology of PAS, is that the defect of endometrial-myometrial layer leads to an abnormal decidualization uterine scar, that provide to abnormally placentation of trophoblast cells to the myometrium [2]. Placenta accreta spectrum can affect all sites in the uterine cavity, but absence of endometrial reepithelialization of the scar area after previous cesarean section or myomectomy, increases significantly the probability of complications in this area. There are many risk factors for placenta accreta spectrum, the most common are: previous cesarean section or myomectomy, placenta previa, advanced maternal age,

\section{Corresponding author:}

Ewa Banas

Clinical Department of Perinatology, Gynaecology and Obstetrics in Ruda Slaska, Medical

University of Silesia, Ruda Slaska, Poland

e-mail:ewa_banas@wp.pl

Received: 18.02.2021 Accepted: 15.06.2021 Early publication date: 10.02.2022

This article is available in open access under Creative Common Attribution-Non-Commercial-No Derivatives 4.0 International (CC BY-NC-ND 4.0) license, allowing to download articles and share them with others as long as they credit the authors and the publisher, but without permission to change them in any way or use them commercially. 
Asherman's syndrome, endometriosis, pelvic inflammatory disease or septic miscarriage in history [3-6].

The incidence of abnormally implanted placenta has increased dramatically over the last decades, which is associated with an increase in the number of cesarean sections. Involved approximately $0.2 \%$ of all pregnancies, reaches from 1 in 2500 pregnancies to 1 in 500 pregnancies [7]. The risk of placenta accreta spectrum increases with the next cesarean section - involved $11 \%$ of pregnancies after two cesarean sections, and even $67 \%$ after four $[5,6]$. Cesarean section is one of the most common procedures in obstetrics and perinatology. Initially this procedure was performed to protect the life and health of mother and newborn. Nowadays repeatedly performed on request or without explicit obstetric indications. In 1985 when the cesarean section became widely used in obstetrics, the World Health Organization recommended, that the number of cesarean sections should not exceed $10-15 \%$ of all births in the world [8]. According to world data, every fourth baby is born by cesarean section. Like any surgery, the cesarean section can lead to many complications - short- and long-term risk, which can extend beyond the current delivery and affect future pregnancies. Review and analysis of medical literature were performed and concluded that at population level, cesarean section rates higher than $10 \%$ dose not reduce the number of maternal and newborn mortality complications $[9,10]$. Unfortunately, the lack of public awareness and trivializing the nature of the operation led to the illusion that cesarean section is a safe operation and does not bring any threat to a woman's life and health. The most common maternal complications post operation were postpartum hemorrhage, wound infections, uterine atony, bladder and ureter damage, intestine damage, coagulopathy, perinatal hysterectomy and invasive placentation [11-13].

Prenatal diagnosis of placenta invasion is very important, it can reduce significantly maternal morbidity and mortality, and allows to plan the surgery, prepare the blood products or gather the most experience surgeons. The most basic diagnostic tool, apart from the clinical evaluation of the patient, is an ultrasound examination (USG). Ultrasound imagination in one of the most common diagnostic tools with a high specificity and sensitivity. Magnetic resonance imaging (MRI) may also be helpful in the diagnosis, but it is not recommended to the systematic use $[14,15]$. There is no statistically significant difference in sensitivity or specificity between ultrasound and MRI. It is useful to diagnose the degree of invasion in case of posterior placenta previa or penetration to the bladder or other adjacent tissues [16].

The sub-placental vascularity and loss of clear zone is the most characteristic ultrasound signs in cases of placenta accreta spectrum. Placenta lacunae, which present as numerous of irregular spaces of varying size in placenta with turbulent flow is a single sing with a high-sensitivity and good positive predictive value. However, there are no ultrasound sings to determination the depth of accreta placentation [17-19].

It is possible to separate placenta creta with subsequent curettage of the uterine cavity, which allows the uterus to be left behind. In the case of an increta and percreta, obstetric hysterectomy is the method of choice [20]. It is one of the most difficult operations in gynecology and obstetrics, most often performed for life reasons. Due to the change in anatomical conditions and direct changes in the pelvic tissues, this procedure requires a lot of experience and precision on the part of the operating team [2]. Surgery is associated with a high percentage of intraoperative complications, such as: damage to the bladder wall, ligation or damage to the ureters, damage to the appendages, hemorrhagic shock, and disseminated intravascular coagulation (DIC). The risk of death reaches $6 \%$, blood loss may exceed $3000 \mathrm{~mL}$ [20].

\section{MATERIAL AND METHODS}

The articles data is a part of bigger project about placenta accrete spectrum, the goal of which is to create an algorithm of management in hospitals, when the placenta increta or percreta is diagnosed. This research work is retrospective, included medical data of pregnant patients with diagnosed prenatally placenta creta, increta or percreta. The research is carried out in the Clinical Department of Perinatology, Gynecology and Obstetrics in Ruda Śląska, which is a 3rd level reference department. The data was collected based on the patients' medical records. The inclusion criterion was the suspicion or diagnosis of placenta accreta spectrum. For this article the additional criterion is also patient age. Numerous variables were analyzed, that could have influenced therapeutic management. Parameters such as numbers of previous cesarean sections, patient age, USG and magnetic resonance imaging results, prenatal complications, blood loss, short and long terms complications and operating technique were examined.

The study received the opinion of the Bioethical Committee of Silesian Medical Chamber in Katowice (ŚIL/KB/76p/19), 14.01.2019. Retrospective study, without the features of an experimental study. Does not require the consent of the bioethics committee.

Due to the character of article, only simple statistical analysis was used. The focus of the work was creating an algorithm, numerical data such as the patient's gestational age, blood loss or hospitalization time were used to determine the best therapeutic effect.

\section{RESULTS}

From the group of 40 patients, seven women under or 30 were selected. All women were hospitalized in the 
Clinical Department of Perinatology, Gynecology and Obstetrics Department in Ruda Śląska, were they also have cesarean section. The age of the respondents was in the range 19-30 years old, the average age is 26 . The gestational age on the day of cesarean section was in the range $31+0-37+4$ weeks of pregnancy, medium $34+3$ weeks of pregnancy. One patient had two cesarean sections before, six of them had only one cesarean section in medical history. The mean hospitalization time was 24 days, in most cases, the hospitalization time was extended due to the waiting for the child's discharge. In one case, the pregnancy was a twin pregnancy type two placentas, two amniotic sacks — hystopatological examination confirmed placenta increta only in one placenta, second was correct.

Placenta previa coexisted in six patients with a diagnosed placenta accreta spectrum, among them three central and three marginal placenta were diagnosed. One patient with no history of placenta previa was clinically diagnosed placenta creta, there was excessive bleeding from the placental site during caesarean section.

All patients had ultrasound examination, two of them also had magnetic resonance imaging (MRI). In this two cases, the MRI image was consistent with histopathological diagnosis. On admission to the ward, blood was reserved for each patient so that the transfusion could be performed at any time. In two patients the day before the planned cesarean section, urological consultation was performed to insert catheters into the ureters. In one case a cystoscopy was performed, due to anatomical changes an unsuccessful attempt to insert the probes. In five cases the cesarean section was performed electively, in two cases - urgently. The indications for an urgent caesarean section were vaginal bleeding and uterine contractions. The majority of patients were operated on under general endotracheal anesthesia. In five cases the hysterectomy was performed. Total caesarean section with perioperative hysterectomy was $148 \mathrm{~min}$ utes, the minimum time was 90 minutes. The operation lasted maximally 220 minutes.

In most cases, caesarean section with perioperative hysterectomy was as follows: after disinfection of the surgical field, the sheaths were opened in layers by straight incision, then the uterus was incised longitudinally to extract the fetus. In all cases, $0.1 \mathrm{mg}$ of carbetocin was administered intravenously following the extraction of the fetus. An attempt was made to manually separate the placenta, and if it was impossible to separate the placenta, a decision was made to extirpate the uterus. The placenta was left in the uterus, suturing the uterine muscle with single sutures. Depending on obstetric conditions, an attempt was made to ligate the internal iliac arteries in order to minimize bleeding during surgery. Then, hysterectomy was performed in a classic way. For postoperative bleeding control, the drain was left in Douglas sinus. Only in two patients the coatings were closed deaf, these were patients with a diagnosed placenta creta. Six patients required intrapartum transfusion of blood, most of them two units of concentrated red blood cells and one unit of fresh frozen plasma. The mean blood loss value was $1270 \mathrm{~mL}$, minimal $600 \mathrm{~mL}$, maximum $2500 \mathrm{~mL}$. No intraoperative complications such as damage to the bladder occurred in any of the patients, anemia was observed in five patients. Two patients required postoperative blood transfusion.

Based on clinical examination during the operation two placenta creta, two increta and three percreta were diagnosed. The uterus with placenta, after the operation underwent a histopathological examination. The final examination confirmed four increta and one percreta. In two cases excessive bleeding from the placental site was a diagnostic criterion for the placenta creta. No patient had any scar defect from the previous cesarean section.

Based on the above analysis of medical records of patients terminated by caesarean section with a diagnosed placenta accreta spectrum. According to the assumptions of the research work, the final analysis and the final version of the procedure algorithm will be created based on a larger number of patient records. A case which is presented below, illustrating the functioning of the procedure algorithm.

\section{Case report}

A 30-year-old woman in second pregnancy, 32 weeks of pregnancy, was admitted to the Clinical Department of Perinatology, Gynecology and Obstetrics Department with bleeding from the uterine. In a medical history placenta previa and prior cesarean section. Upon admission in ultrasound examination no ablation features were found, confirmed central placenta previa. Also has been found the invasion of placenta to the front wall of uterine, especially from left site. As we can see on pictures below (Fig. 1), the basic features of the placenta accreta spectrum diagnosis were met: loss of clear zone between the placenta tissues and myometrium, sub-placental vascularity and numerous of placenta lacunae. The placenta completely covers the internal cervix. The is no features of bleeding from placenta.

MRI was performed during further hospitalization. The study found criteria of extensively invasion of placenta tissues to the uterine wall with penetration through the entire myometrium, especially on the left side (Fig. 2A-2C). Also suspicion of attachment to bladder wall was presented. Two units of blood and two units of fresh-frozen plasma were reserved on admission.

Well-being of the mother and the fetus observed in the ward conditions. Blood and plasma reservations were made. A single course of antenatal corticosteroid therapy was given. In 34 weeks of pregnancy, patient was classified 

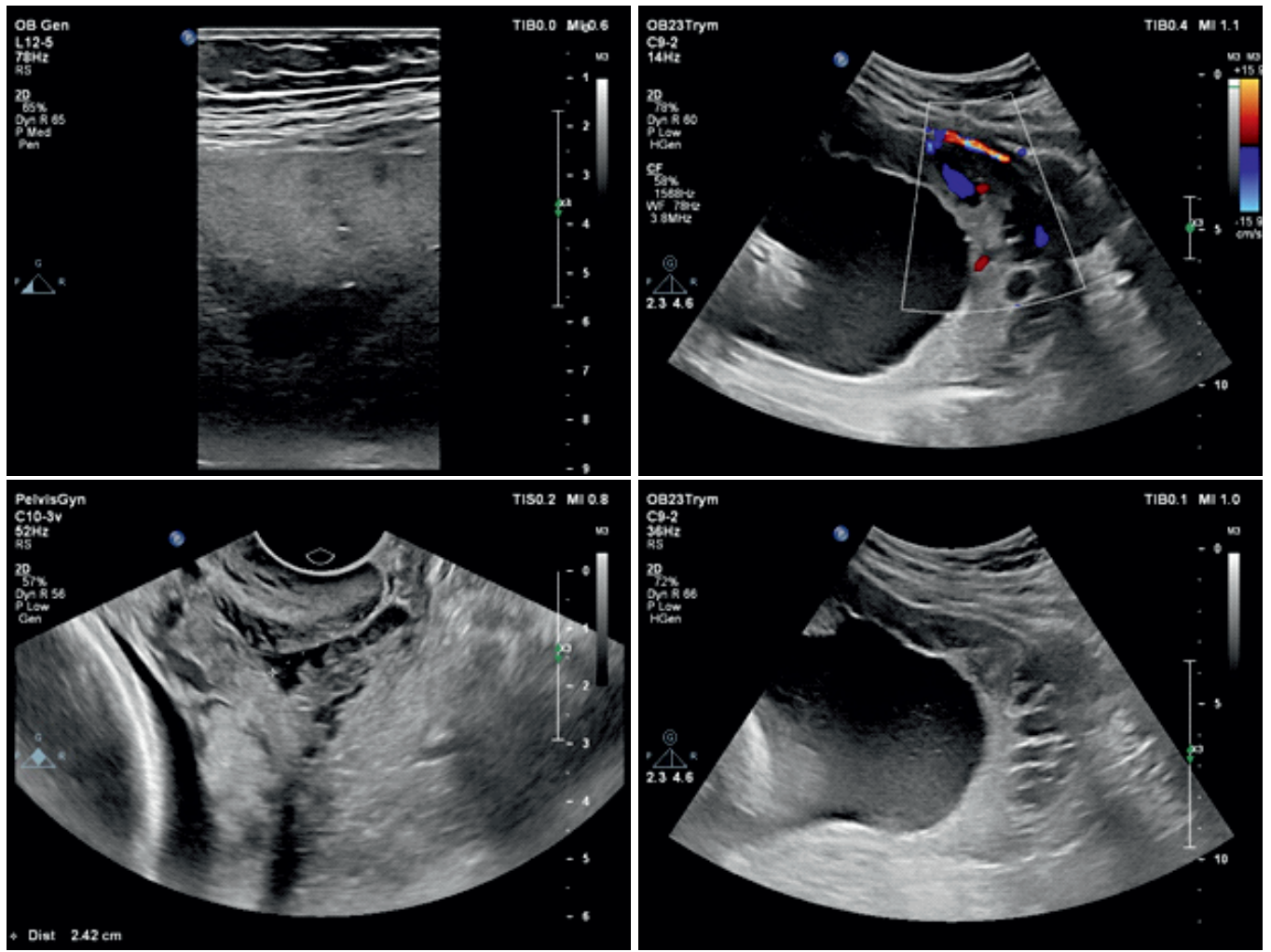

Figure 1. Ultrasound scans of the patient
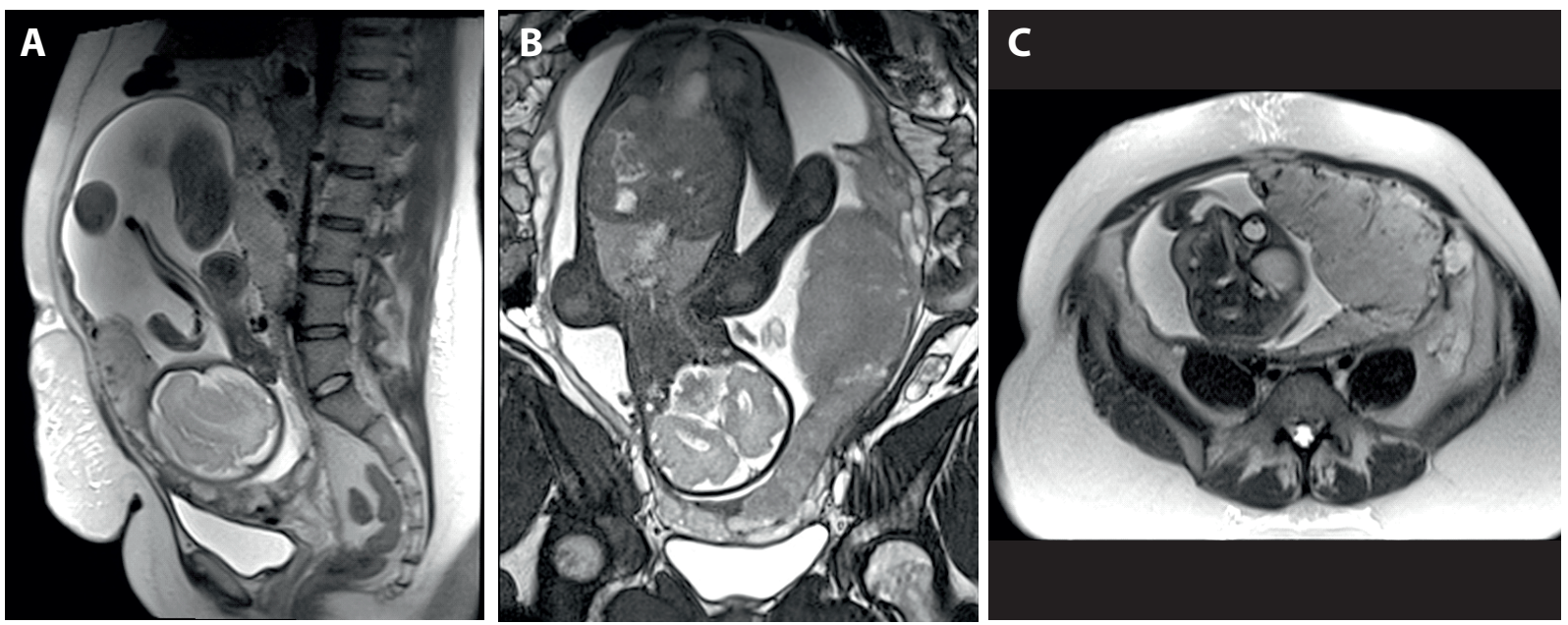

Figure 2. A. HASTE image in the sagittal plane. The placenta covers the inner opening of the cervix, at this level the normal boundary between the uterus and placenta is not visible. Numerous tortuous vessels are visible. At the back wall of the bladder, numerous vessels are also visible, with the continuity of its wall; B. TRUFI image in frontal plane. The placenta is thickened and there is no normal border between the placenta and the uterine muscle. Very thin myometrium. Visible hypotensive bands within the placenta; C. HASTE image in transverse plane. The placenta is thickened, heterogeneous, invisible normal border between the placenta and the uterus. There are hypointense bands within the placenta and numerous vessels on the border of the placenta and the muscle. On the left side, the outer contours of the uterus are segmental highlighted

to planned cesarean section with hysterectomy. The situation was correctly and fully explained to the patient. The procedure was presented from method of tissue cutting, indications to hysterectomy to the high risk of hemorrhage or even a death. The patient had to sign a written consent for caesarean section with possible intraoperative uterine extirpation. Before the operation day patient was consulted in the urology department, where probes for the ureters were inserted. Indication to hysterectomy was clinical diagnosed placenta percreta, massive blood loss, no possible separate 
placenta from uterine wall. Hysterectomy was carried out in the typical way. The uterus with placenta was submitted for histopathological examination (Fig. 3). Newborn was given to a team of neonatologists, and after giving birth obtained 10 Apgar's points. Blood loss reached $1500 \mathrm{~mL}$. After surgery, the hemoglobin value was $9.9 \mathrm{~g} / \mathrm{dL}$. 2 blood units and 1 plasma unit were transfused. Prophylactic antibiotic therapy was applied $-3 \times 1.5 \mathrm{~g}$ Biofuroksym i.v.. The patient was in good general condition in the ward, awaiting the child's discharge.

\section{DISCUSSION}

The main goal of presenting research was to create an algorithm for the management of patients with suspicion or diagnosis of placenta accreta spectrum (Fig. 4). Given the risks of placenta accreta spectrum, an accurate antenatal diagnosis is very important. The basic diagnostic tool available in most medical centers is ultrasound imagine. It is highly accurate when performed by an experienced ultrasound technician with experience in assessing placenta accreta spectrum [19, 21, 22]. There is no data source recommended MR more than ultrasound imagination [23]. Our experience also confirms that a well-performed ultrasound examination is sufficient to diagnose the placenta. MR may be useful in the diagnosis of placenta previa from the posterior wall or the degree of placental invasion into adjacent tissues including the bladder wall [24].
Elective cesarean section is recommended between 35-37 pregnancy weeks, this makes it possible to avoid bleeding from the placenta previa or to perform an immediate caesarean section without prior preparation $[22,25]$.

The RCOG does not recommended the routine use of ureteric catheters, however we found that intubate ureters can be helpful during surgery. Due to adhesions and anatomical changes related to a previous cesarean section, the ureters are often damaged during hysterectomy. Probes in the ureters allow precise determination of the course of the ureters, which reduces the risk of their damage. This may have a big role when the invasion of placenta to bladder is suspicion, also when we recognized the parametrial invasion with a high risk of ureteric injuries during the surgery [26].

Women with a high suspicion or recognized placenta accreta spectrum should be under the care of experienced multi-disciplinary team with experienced in dealing with abnormal invasion of placenta $[22,26]$. It is necessary to provide comprehensive care with immediate availability of blood products, ultrasound or MR imaging, intensive care units and a neonatal intensive care unit.

\section{CONCLUSIONS}

It is necessary to plan individual procedure for women who has low-lying or previa placenta, and who has history

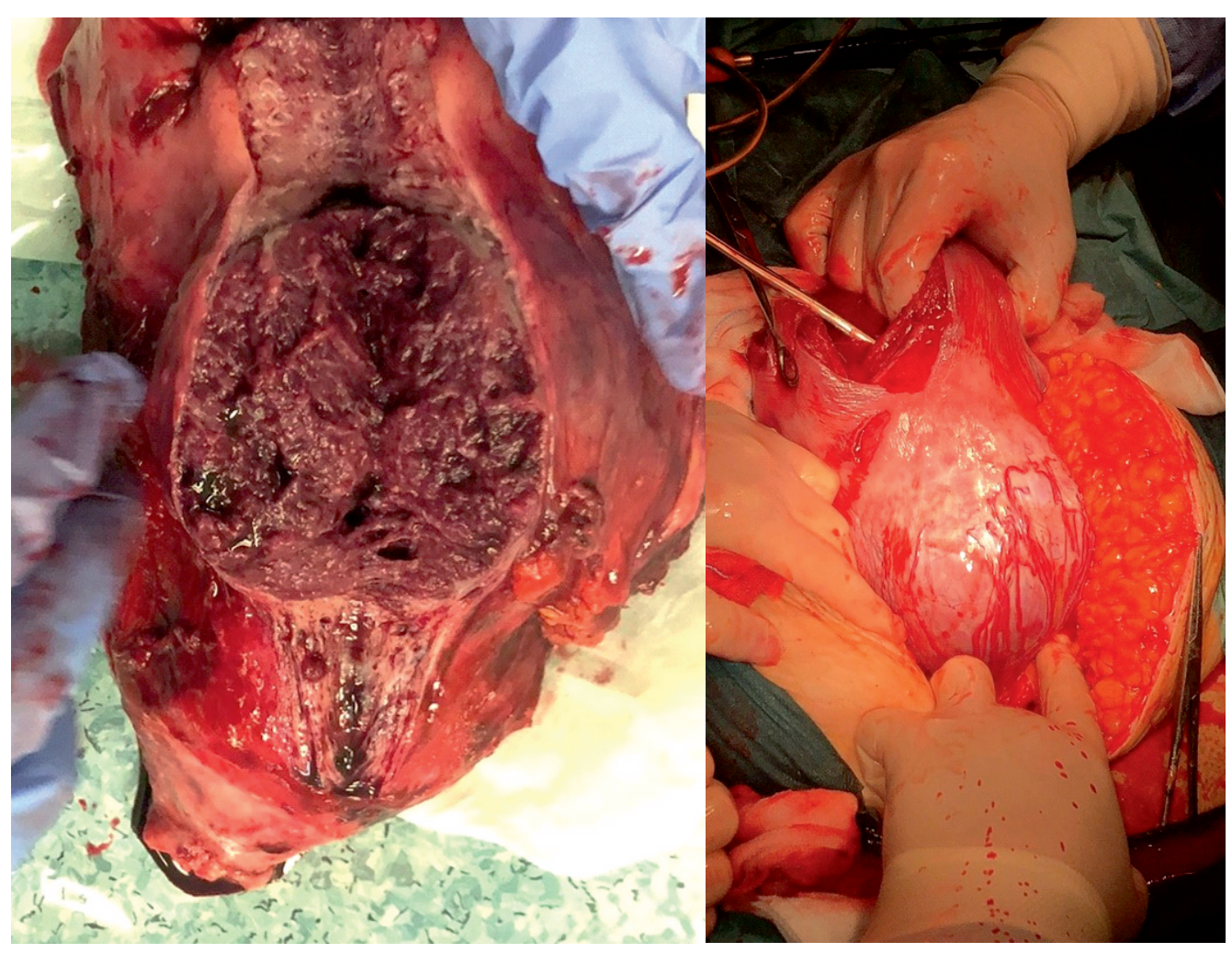

Figure 3. Intraoperative photos showing the uterus with placenta incretta 


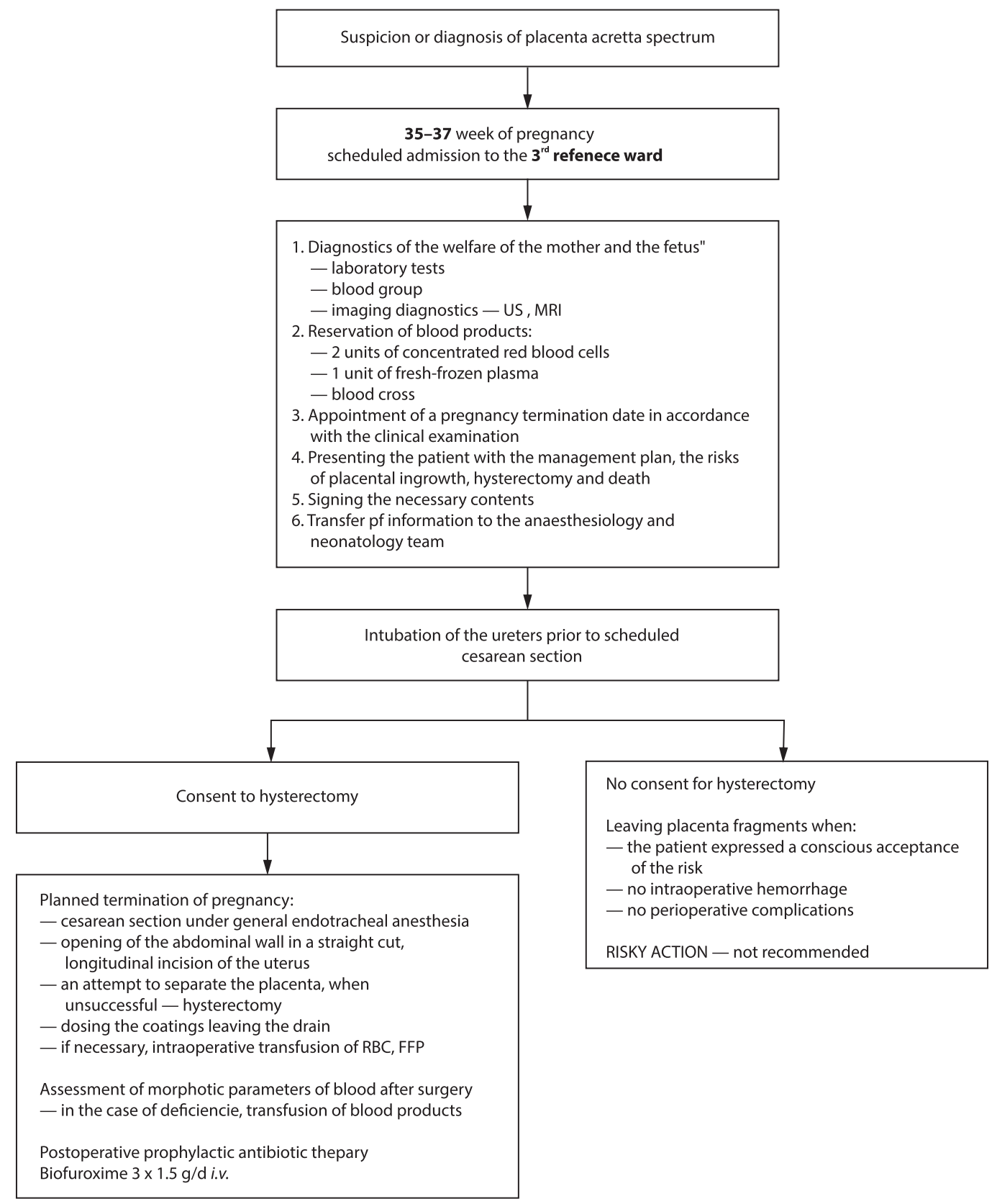

Figure 4. Algorithm of management in the case of placenta accreta spectrum

of prior cesarean section - in this group the risk of placenta accreta spectrum is higher. Unrecognized placenta accreta spectrum can lead to significant increases of morbidity and mortality which is why proper diagnosis and preparation of the patient for childbirth is so important. The patient requires the care of an experienced ultrasound specialist and an obstetrician who will guide the patient's pregnancy in a way that is aware of the risks. Unfortunately, the number of cesarean sections is increasing rapidly these days, including in young women. It is important not only to reduce the number of cesarean sections, but also to learn how to deal with abnormalities such as placenta accreta spectrum.

\section{Acknowledgments}

The authors would like to thank all staff members of the Clinical Department of Perinatology, Gynecology and Obstetrics in Ruda Śląska, Poland who participated in the study for their invaluable contribution to this research.

\section{Conflicts of interest}

The authors declare no conflict of interest. 


\section{REFERENCES}

1. Oyelese Y, Smulian J. Placenta previa, placenta accreta, and vasa previa. Obstetrics \& Gynecology. 2006; 107(4): 927-941, doi: 10.1097/01. aog.0000207559.15715.98.

2. Cahill A, Beigi R, Heine R, et al. Placenta Accreta Spectrum. American Journal of Obstetrics and Gynecology. 2018; 219(6): B2-B16, doi: 10.1016/j.ajog.2018.09.042.

3. Miller D, Chollet J, Goodwin T. Clinical risk factors for placenta previa-placenta accreta. American Journal of Obstetrics and Gynecology. 1997; 177(1): 210-214, doi: 10.1016/s0002-9378(97)70463-0.

4. Carusi DA. The placenta accreta spectrum: epidemiology and risk factors. Clin Obstet Gynecol. 2018; 61(4): 733-742, doi: 10.1097/GRF.0000000000000391, indexed in Pubmed: 30204619.

5. Wlodarz-Ulman I, Nowosielski K, Poreba R, et al. P372 Placenta praevia increta with cesarean section scar invasion. International Journal of Gynecology \& Obstetrics. 2009; 107: S520-S520, doi: 10.1016/s00207292(09)61863-4.

6. Levine D, Hulka CA, Ludmir J, et al. Placenta accreta: evaluation with color Doppler US, power Doppler US, and MR imaging. Radiology. 1997; 205(3): 773-776, doi: 10.1148/radiology.205.3.9393534, indexed in Pubmed: 9393534.

7. Fitzpatrick KE, Sellers S, Spark P, et al. Incidence and risk factors for placenta accreta/increta/percreta in the UK: a national case-control study. PLoS One. 2012; 7(12): e52893, doi: 10.1371/journal.pone.0052893, indexed in Pubmed: 23300807.

8. Chalmers B. WHO appropriate technology for birth revisited. Br J Obstet Gynaecol. 1992; 99(9): 709-710, doi: 10.1111/j.1471-0528.1992. tb13867.x, indexed in Pubmed: 1420006.

9. Ye J, Zhang J, Mikolajczyk R, et al. Association between rates of caesarean section and maternal and neonatal mortality in the 21st century: a worldwide population-based ecological study with longitudinal data. BJOG. 2016; 123(5): 745-753, doi: 10.1111/1471-0528.13592, indexed in Pubmed: 26331389.

10. Betran AP, Torloni MR, Zhang J, et al. What is the optimal rate of caesarean section at population level? A systematic review of ecologic studies. Reprod Health. 2015; 12: 57, doi: 10.1186/s12978-015-0043-6, indexed in Pubmed: 26093498

11. Sharma S, Dhakal I. Cesarean Vs Vaginal Delivery: An Institutional Experience. Journal of Nepal Medical Association. 2018; 56(209): 535-539, doi: 10.31729/jnma.3467.

12. Gill P, Patel A, Van Hook JW. Uterine Atony. 2018, indexed in Pubmed: 29630290.

13. Huls C. Cesarean hysterectomy and uterine-preserving alternatives. Obstetrics and Gynecology Clinics of North America. 2016;43(3): 517-538, doi: 10.1016/j.ogc.2016.04.010.

14. Thiravit S, Lapatikarn S, Muangsomboon K, et al. MRI of placenta percreta: differentiation from other entities of placental adhesive disorder. Radiol Med. 2017; 122(1): 61-68, doi: 10.1007/s11547-016-0689-3, indexed in Pubmed: 27651244.
15. Jauniaux E, Collins S, Burton GJ. Placenta accreta spectrum: pathophysiology and evidence-based anatomy for prenatal ultrasound imaging. Am J Obstet Gynecol. 2018; 218(1): 75-87, doi: 10.1016/j.ajog.2017.05.067, indexed in Pubmed: 28599899.

16. D'Antonio F, lacovella C, Palacios-Jaraquemada J, et al. Prenatal identification of invasive placentation using magnetic resonance imaging: systematic review and meta-analysis. Ultrasound Obstet Gynecol. 2014; 44(1): 8-16, doi: 10.1002/uog.13327, indexed in Pubmed: 24515654

17. Baughman WC, Corteville JE, Shah RR. Placenta accreta: spectrum of US and MR imaging findings. Radiographics. 2008; 28(7): 1905-1916, doi: 10.1148/rg.287085060, indexed in Pubmed: 19001647.

18. Piñas Carrillo A, Chandraharan E. Placenta accreta spectrum: risk factors, diagnosis and management with special reference to the Triple $P$ procedure. Womens Health (Lond). 2019; 15: 1745506519878081 , doi: 10.1177/1745506519878081, indexed in Pubmed: 31578123.

19. Jauniaux E, Collins SL, Jurkovic $D$, et al. Accreta placentation: a systematic review of prenatal ultrasound imaging and grading of villous invasiveness. Am J Obstet Gynecol. 2016; 215(6):712-721, doi: 10.1016/j. ajog.2016.07.044, indexed in Pubmed: 27473003.

20. Piñas Carrillo A, Chandraharan E. Placenta accreta spectrum: Risk factors, diagnosis and management with special reference to the Triple P procedure. Womens Health (Lond). 2019; 15: 1745506519878081 , doi: 10.1177/1745506519878081, indexed in Pubmed: 31578123.

21. Jauniaux E, Bhide A, Kennedy A, et al. FIGO Placenta Accreta Diagnosis and Management Expert Consensus Panel. FIGO consensus guidelines on placenta accreta spectrum disorders: prenatal diagnosis and screening. Int J Gynaecol Obstet. 2018; 140(3): 274-280, doi: 10.1002/ijgo.12408, indexed in Pubmed: 29405319.

22. Jauniaux E, Alfirevic Z, Bhide AG, et al. Royal College of Obstetricians and Gynaecologists. Placenta Praevia and Placenta Accreta: Diagnosis and Management: Green-top Guideline No. 27a. BJOG. 2019; 126(1): e1-e48, doi: 10.1111/1471-0528.15306, indexed in Pubmed: 30260097.

23. D'Antonio F, lacovella C, Palacios-Jaraquemada J, et al. Prenatal identification of invasive placentation using magnetic resonance imaging: systematic review and meta-analysis. Ultrasound Obstet Gynecol. 2014; 44(1): 8-16, doi: 10.1002/uog.13327, indexed in Pubmed: 24515654.

24. Lax A, Prince MR, Mennitt KW, et al. The value of specific MRI features in the evaluation of suspected placental invasion. Magn Reson Imaging. 2007; 25(1): 87-93, doi: 10.1016/j.mri.2006.10.007, indexed in Pubmed: 17222719.

25. Allen L, Jauniaux E, Hobson S, et al. FIGO Placenta Accreta Diagnosis and Management Expert Consensus Panel. FIGO consensus quidelines on placenta accreta spectrum disorders: Nonconservative surgical management. Int J Gynaecol Obstet. 2018; 140(3): 281-290, doi: 10.1002/ijgo.12409, indexed in Pubmed: 29405317.

26. American College of Obstetricians and Gynecologists, Society for Maternal-Fetal Medicine. Obstetric Care Consensus No. 7: Placenta Accreta Spectrum. Obstet Gynecol. 2018; 132(6): e259-e275, doi: 10.1097/AOG.0000000000002983, indexed in Pubmed: 30461695. 